\title{
BMJ Open Is the fluorescence optical imaging (FOI) able to discriminate between rheumatoid arthritis patients with and without need of rituximab retherapy? A cohort study
}

\author{
Schahrasad Lisa Ridha Ali, ${ }^{1}$ Anne-Marie Glimm, ${ }^{1}$ Gerd R Burmester (D) , ${ }^{1}$ \\ Paula Hoff, ${ }^{1}$ Gabriela Schmittat, ${ }^{1}$ Sandra Hermann, ${ }^{1}$ Marina Backhaus, ${ }^{1,2}$ \\ Jens Klotsche, ${ }^{3,4}$ Sarah Ohrndorf (1) ${ }^{1}$
}

To cite: Ridha Ali SL, Glimm A$\mathrm{M}$, Burmester GR, et al. Is the fluorescence optical imaging (FOI) able to discriminate between rheumatoid arthritis patients with and without need of rituximab retherapy? A cohort study. BMJ Open 2021;11:e047713. doi:10.1136/ bmjopen-2020-047713

- Prepublication history and additional supplemental material for this paper are available online. To view these files, please visit the journal online (http://dx.doi.org/10.1136/ bmjopen-2020-047713).

SLRA and A-MG contributed equally.

Received 15 December 2020 Accepted 07 July 2021

Check for updates

(C) Author(s) (or their employer(s)) 2021. Re-use permitted under CC BY-NC. No commercial re-use. See rights and permissions. Published by BMJ.

For numbered affiliations see end of article.

Correspondence to Dr Sarah Ohrndorf; sarah.ohrndorf@charite.de

\section{ABSTRACT}

Objective To evaluate the ability of fluorescence optical imaging (FOI) Xiralite in the discrimination between rheumatoid arthritis (RA) patients with and without need of rituximab (RTX) retherapy - in comparison to clinical, laboratory and musculoskeletal ultrasound parameters. Patients and methods Patients with established RA were prospectively followed over 1 year by Disease Activity Score 28, patient's global disease activity (visual analogue scale $0-100 \mathrm{~mm}$ ), C reactive protein and erythrocyte sedimentation rate, ultrasound seven joint (US7) score and FOI in phases 1-3 and automatically generated PrimaVista mode (PVM) at baseline (before RTX) and after 3, 6 and 12 months. The need for RTX retherapy was decided by the treating rheumatologist—blinded to imaging data.

Results 31 patients (female $77.4 \%$, mean age $60.1 \pm 11.4$ mean disease duration $14.9 \pm 7.1$ years) were included. Fourteen (45.2\%) patients received RTX retherapy within 12 months. In the group with RTX retherapy, FOI in PVM mode was the only parameter that presented significant increase over time ( $\beta$ : $0.40,95 \% \mathrm{Cl}: 0.08$ to 0.71 , $\mathrm{p}=0.013$ - — compared with the group without retherapy. In the prediction model via ROC analysis, FOI in PVM reached the highest values of all imaging, clinical and laboratory parameters which was associated with retherapy over 1 year with an area under the curve (AUC) of 0.78 (OR: $0.84,95 \% \mathrm{Cl}: 0.72$ to $0.98, p=0.031)$. US7 GS synovitis score revealed similar association with an AUC of 0.73 $(p=0.049)$.

Conclusion US7 GS synovitis score and FOI in PVM are able to discriminate between patients with and without need for RTX retherapy better than clinical and laboratory parameters.

\section{INTRODUCTION}

Rheumatoid arthritis (RA) is a chronic multisystemic autoimmune disease with a persistent inflammatory synovitis leading to cartilage and bone destruction such as erosions with consecutive joint deformities. In order to avoid corresponding complications,

\section{Strengths and limitations of this study}

More objective methods for the decision of rituximab (RTX) retherapy (eg, imaging) are needed in order to detect subclinical disease activity and an upcoming flare in patients with rheumatoid arthritis.

- Fluorescence optical imaging (FOI) with the Xiralite system as a novel imaging tool is able to help in decision-making for RTX retherapy since it can discriminate in PrimaVista mode (PVM) between patients with and without need of RTX retherapy better than other imaging, laboratory and clinical parameters.

- At the same time, FOI is a more objective tool, while Disease Activity Score 28, patient's visual analogue scale and $C$ reactive protein also depend on other influence (ie, psychological, infectious) factors.

- Consideration should therefore be given to including objective factors such as FOI in PVM in the decision on RTX retherapy.

- In order to fully consolidate these results, further FOI studies on larger scales are required since the number of included patients into the study was limited.

an effective therapy should be started immediately after the diagnosis of RA has been made. ${ }^{1}$ If conventional synthetic diseasemodifying antirheumatic drugs (csDMARDs) or TNF inhibitors operate inadequately or are not tolerated, rituximab (RTX) as monoclonal anti-CD20 antibody can be applied. ${ }^{23}$ A retherapy with RTX is recommended after 24 weeks if there has been an improvement of Disease Activity Score 28 (DAS28) more than 1.2 and either a residual disease activity (DAS28 >3.2) or a new increase of disease activity after initial response (increase of DAS28 >0.6). ${ }^{2}{ }^{4}$ Because of the subjective part of DAS28 (visual analogue scale, VAS) in decision-making, ${ }^{4}$ more objective methods 
for the decision of RTX-retherapy (eg, imaging) are needed in order to detect subclinical disease activity and an upcoming flare before the patients will show clinical symptoms. ${ }^{5}$ For therapy monitoring, different imaging methods are applied including MRI and musculoskeletal ultrasound (US) which provide an objective and reliable presentation of the current (sub)clinical disease activity. ${ }^{5-10}$ In a previously published study, a predictive value for retherapy with RTX by using power Doppler (PD) mode in US could be presented. ${ }^{5}$

The fluorescence optical imaging (FOI) by the Xiralite method detects disturbed microcirculation in the joints of both hands by using indocyanine green (ICG). Previous studies have shown good correlation of FOI with MRI and US in synovitis detection. ${ }^{11} 12$

The current study aimed at the analyses whether FOI is able to discriminate between RA patients with and without need of RTX retherapy. For this, FOI findings were compared with clinical, laboratory and US (ultrasound seven joint score, US7 score) parameters.

\section{Patients and methods}

The observational study was performed at the outpatient clinic of the Department of Rheumatology and Clinical Immunology at the Charité - Universitätsmedizin Berlin, Germany.

\section{Patient and public involvement}

Patients were included after written and oral consent following a detailed description of the study including the research question and outcome measures. Inclusion criteria were a confirmed diagnosis of RA according to 1987 or 2010 criteria, ${ }^{13}{ }^{14}$ insufficient response to TNF inhibitors, age $>18$, psychological understanding of risk and side effects of the study and consent to participate in the study. Patients were neither involved in the design of the study nor in the recruitment to and conduct of the study.

\section{Clinical and laboratory parameters}

The clinical investigation included the examination of tender and swollen joints (TJC-28 and SJC-28). From this, DAS28 (erythrocyte sedimentation rate, ESR) was calculated by additional application of patient's global VAS (0-100 mm) and ESR (hour/mm) before RTX therapy and after 3, 6 and 12 months. Next to ESR, the laboratory testing included $\mathrm{C}$ reactive protein (CRP, normal $<5.0 \mathrm{mg} / \mathrm{L})$ at the follow-up visits, and rheumatoid factor (RF-IgM, $\mathrm{n}<20 \mathrm{IU} / \mathrm{mL}$ ) and anticitrullinated antibodies (ACPA, $\mathrm{n}<20 \mathrm{IU} / \mathrm{mL}$ ) at baseline.

\section{Musculoskeletal US examination (US7 score)}

The US examination (Esaote Mylab Twice (Genova, Italy)) using the US7 score ${ }^{6}$ was performed before intravenous application of RTX (baseline), and after 3, 6 and 12 months. The US7 includes the investigation of the wrist (dorsal, palmar and ulnar), the metacarpophalangeal joints (MCP) 2 and 3, the proximal interphalangeal (PIP) joints 2 and 3 of the clinically dominant hand, and the metatarsophalangeal (MTP) joints 2 and 5 of the clinically dominant forefoot on dorsal and palmar/plantar sides by greyscale (GS) and PD mode. The standard performance of the US7 refers to the simultaneous evaluation of synovitis and tenosynovitis, and the included joints (except the wrist) were also examined from dorsal and palmar/plantar for erosions, additionally MCP2 from radial and MTP5 from lateral. Synovitis in GS and PD and tenosynovitis in PD were assessed semiquantitatively; tenosynovitis in GS and erosions were evaluated if they were present or not $(1 / 0) .{ }^{5-8}$

\section{Fluorescence optical imaging}

The FOI was performed by the Xiralite 4 system (Xiralite $\mathrm{GmbH}$, Berlin, Germany). FOI images were taken before the beginning of RTX therapy and after 3, 6 and 12 months in a standardised manner. Ten seconds after beginning the examination, a bolus of $0.1 \mathrm{mg} / \mathrm{kg} /$ body weight of the fluorescent dye ICG was intravenously applied. The examination lasted 6 min recording one image per second and adding up to a cluster of 360 images. The examination included 30 joints of both hands (the wrist, MCP joints, PIP joints, (D)IP joints of both hands). The analyses of the images comprised the evaluation of the first 240 images forming the automatically generated PrimaVista mode (PVM). In addition, three phases in position to the fingertips with regard to development of signal intensities were defined and analysed, for further information please see online supplemental material.

\section{Statistical analysis}

Standard descriptive statistics were used to report patients' characteristics and the course of clinical, US and FOI parameters at each visit within 12 months. The change of disease activity parameters, US7 scores and FOI across 12 months was analysed by generalised linear mixed-models for the total sample and separately for patients with and without RTX retherapy through follow-up visits. The three patients missed in follow-up visits were included in the analyses and the linear mixed-model resulted in unbiased estimates by the maximum likelihood approach, because we could not investigate a selection bias by the three patients. Additionally, since FOI only considers the joints of the hands, the data of the forefoot in US were excluded from statistical analyses for comparability.

Mann-Whitney U test was used to compare the parameters between patients with and without RTX re-therapy at each visit.

Furthermore, logistic regression analyses were conducted to model the likelihood for a retherapy with RTX within 12 months by DAS28, US7 score and FOI. Area under the curve (AUC) was estimated after fitting the logistic regression model to assess the predictive value for each parameter for retherapy with RTX. The strength of association can be compared between variables by the AUC because it does not depend on the dimension of the analysed variable. The level of significance was defined by 
$\alpha<0.05$. The statistical analysis was conducted in STATA V.12.1.

\section{RESULTS}

\section{Total patient group}

Thirty-one patients were examined at baseline, $\mathrm{n}=29$ after 3 months, and $n=28$ after 6 and 12 months (three patients lost to follow-up). The included patients (24 females) revealed a mean age of $60.1 \pm 14.9$ years and mean disease duration of $14.9 \pm 7.1$ years. About $96.8 \%$ of the patients were rheumatoid factor (RF-IgM) positive and 93.6\% ACPA positive. Twenty-eight patients received a therapy with other biological DMARDs (TNF or interleukin-6 (IL-6) inhibitors) before treatment with RTX was started. Reasons for discontinuing previous drug treatment were non-response (40.0\%), insufficient effectiveness (46.7\%), contraindications (16.7\%) and adverse events (46.7\%). Seventeen patients had already received RTX before being included in the study. This aspect did not influence the course of the parameters during the 12 months. Concomitant to RTX, 29.1\% of the patients had ongoing therapy with methotrexate, $12.9 \%$ with leflunomide, $6.5 \%$ with sulfasalazine, $9.7 \%$ with hydroxychloroquine and $3.2 \%$ with azathioprine at baseline.

Please see the changes of clinical (DAS28), laboratory (CRP/ESR) and imaging parameters (US7 score; FOI) in the total study population in the online supplemental table $\mathrm{S} 1$ and figure $\mathrm{S} 1$.

\section{Patients with RTX retherapy}

Of the total 31 patients, $n=14$ received a retherapy with RTX (45.2\%) within 12 months observational period; $\mathrm{n}=3$ after 6 months, $n=4$ after 7 months, $n=5$ after 9 months, and $\mathrm{n}=2$ after 10 months.

The parameters DAS28 and patient's global VAS decreased significantly in this group (mean of DAS28 at baseline 5.1, after 12 months $3.9, \mathrm{p}=0.004$; mean patient's global VAS at baseline $59.6 \mathrm{~mm}$, after 12 months $45 \mathrm{~mm}$, $\mathrm{p}=0.042$ ).

FOI in PVM singularly significantly increased (mean $7.8 \pm 4.3 ; 15.2 \pm 10.4, \mathrm{p}=0.013)$ in comparison to the other imaging parameters (see table 1 ).

During the observed period, half of the patients who received RTX retherapy had a concomitant csDMARD therapy (at baseline $57.1 \%, \mathrm{n}=8$; after 12 months 50\%, $\mathrm{n}=7$ ). Glucocorticoids were additionally used by $85.7 \%$ $(\mathrm{n}=12)$ with a mean daily dosage of $9.3 \mathrm{mg}$ (SD: 8.0) and were less needed over the following 6 months (after 3 months $78.6 \%, \mathrm{n}=11$ with a daily dosage of $5.8 \mathrm{mg}$ (SD: 5.1 ), after 6 months $78.6 \%, \mathrm{n}=11$ with a daily dosage of $6.5 \mathrm{mg}$ (SD: 5.1)), and after retherapy with RTX, that is, after 12 months in $71.4 \%(\mathrm{n}=10)$ with a daily dosage of $5.3 \mathrm{mg}$.

\section{Patients without RTX re-therapy}

Seventeen patients of the total patient group did not receive a retherapy with RTX during the observed 12 months. In this group, a significant decrease between baseline and 12 months follow-up was shown for the patient's global VAS, US7 GS synovitis, US7 GS tenosynovitis, US7 PD tenosynovitis and FOI in phase 2 (table 1; an FOI image example is also presented by figure 1 ). The clinical parameters did not significantly change in that group. The ESR after 12 months was significantly higher than in the group with retherapy $(\mathrm{p}=0.033$, see online supplemental table S2). Regarding FOI, signal enhancement in phase 2 was singularly reduced in a significant manner (mean $33.9 \pm 15.8$ to $28.2 \pm 17.3, \mathrm{p}=0.008$ ). PVM remained stable in this group.

The use of csDMARDs and glucocorticoids decreased continuously over 1 year (csDMARDs at baseline $60 \%$, $\mathrm{n}=9$, after 12 months $50 \%, \mathrm{n}=7$ and glucocorticoids at baseline $86.7 \%, \mathrm{n}=13$ with a mean daily dosage of 5.4 (SD: 2.7 ), after 12 months $78.6 \%, \mathrm{n}=11$ with a mean daily dose of $4.5 \mathrm{mg}$ (SD: 2.3)).

Information on results of month 3 and 6 is given in the supplementary material and in online supplemental table S2.

\section{Prediction for RTX retherapy}

The likelihood for an RTX retherapy (after 6 months) was analysed by considering the predictive value of the change between baseline and 3 months or 6 months follow-up in clinical and patient-reported parameters. The change in DAS28, ESR and CRP as well as patientreported parameters were not associated with the initiation of an RTX retherapy (AUC close to 0.5). On the other side, the likelihood of an RTX retherapy was significantly associated with the change between baseline and 6 months follow-up in the imaging parameters US7 GS synovitis score $(\mathrm{AUC}=0.73)$ and $\mathrm{FOI}$ in PVM $(\mathrm{AUC}=0.78)$ (see table 2). The FOI in PVM was significantly associated with the likelihood of an RTX retherapy in multivariable analysis including the US7 GS synovitis score.

\section{DISCUSSION}

The aim of this study was the evaluation of FOI for its ability to visualise the need for RTX retherapy in patients with RA in comparison to clinical, laboratory and musculoskeletal US (US7 score) parameters. To our knowledge, this was assessed for the first time for FOI.

We found out that the clinical and laboratory parameters DAS28, patient's global VAS and CRP decreased significantly over 1 year under RTX-therapy in all patients. A decrease of the US7 synovitis and tenosynovitis GS scores was also presented. All reduced parameters thereby represented a response to RTX.

All patients received csDMARDs additionally to RTX according to EULAR recommendations. ${ }^{2}$ The use of glucocorticoids and the dose of glucocorticoids could be advantageously reduced in the patients without RTX retherapy to a mean daily dosage of $4.5 \mathrm{mg}$ after 12 months, whereas the patients with RTX re-therapy still had a mean daily dosage of $5.3 \mathrm{mg}$. 
Table 1 Changes of clinical, laboratory and imaging parameters over 12 months follow-up

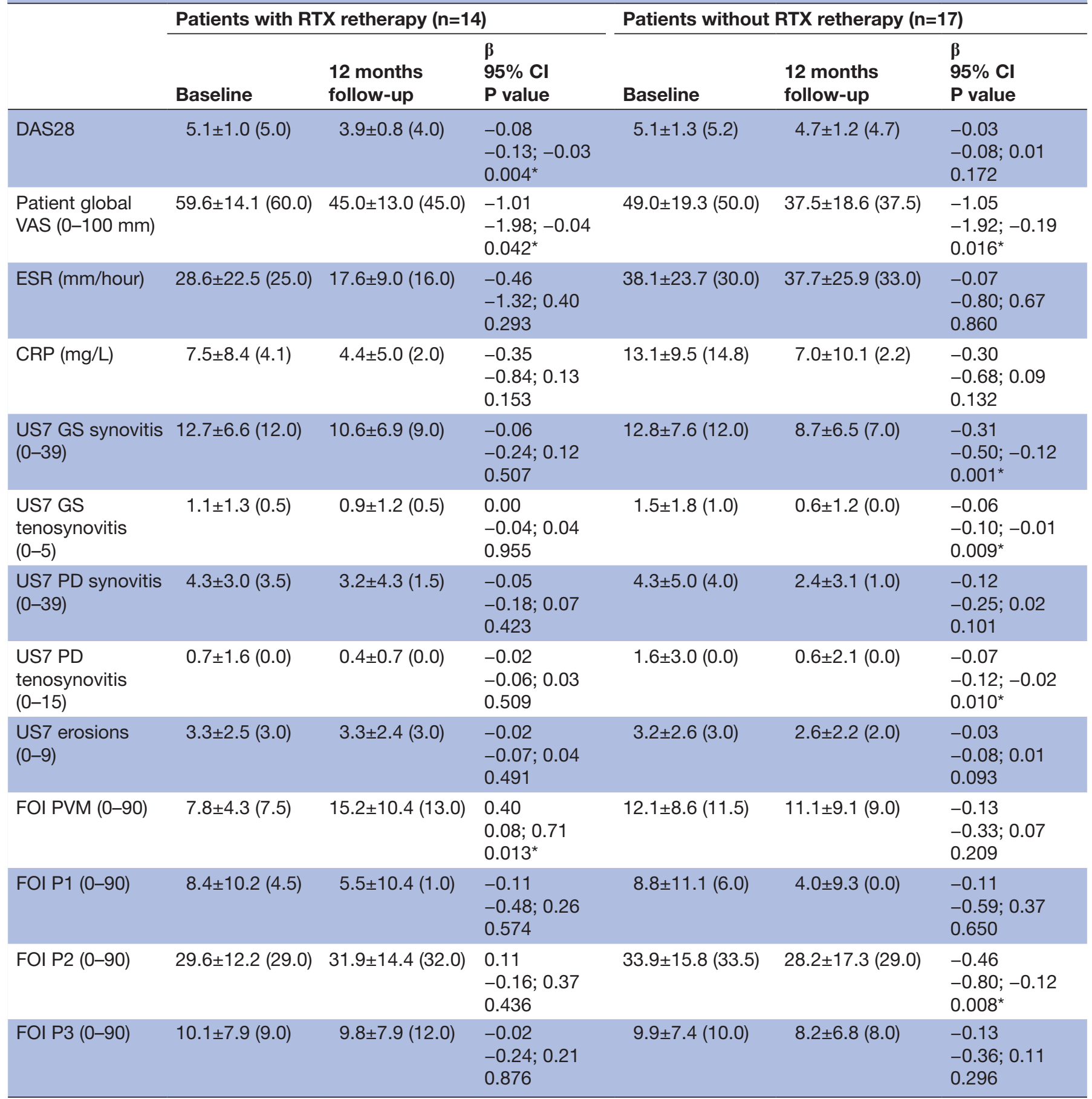

Changes of clinical, laboratory and imaging parameters over 12 months follow-up in mean \pm standard deviation (median) and $\mathrm{p}$ value for significant change over time: $\beta$ as change after 12 months; $95 \% \mathrm{Cl}$.

${ }^{*} \mathrm{P}$ value for significant change over time.

CRP, C reactive protein; DAS28, Disease Activity Score 28; ESR, erythrocyte sedimentation rate; FOI, fluorescence optical imaging; GS, greyscale; P1,2,3, FOI phases 1,2,3 (0-90); PD, power Doppler; PVM, PrimaVista mode (0-90); RTX, rituximab; US7, ultrasound seven joint score; VAS, visual analogue scale.

Moreover, all patients (except one) were positive for $\mathrm{RF}$ and ACPA. This aspect corresponds with the results of previous studies, in which a high RTX response after an insufficient response to TNF inhibitors was mainly demonstrated in patients who were RF positive and ACPA-positive. ${ }^{15}$
Due to the residual disease activity of DAS28 of more than 3.2 and taking physician's statement into account, 14 patients received a retherapy with RTX according to consensus agreement ${ }^{2}$ in this 1 year follow-up study. In the group of RTX retherapy, DAS28 and patient's global VAS decreased significantly, while we could not calculate 

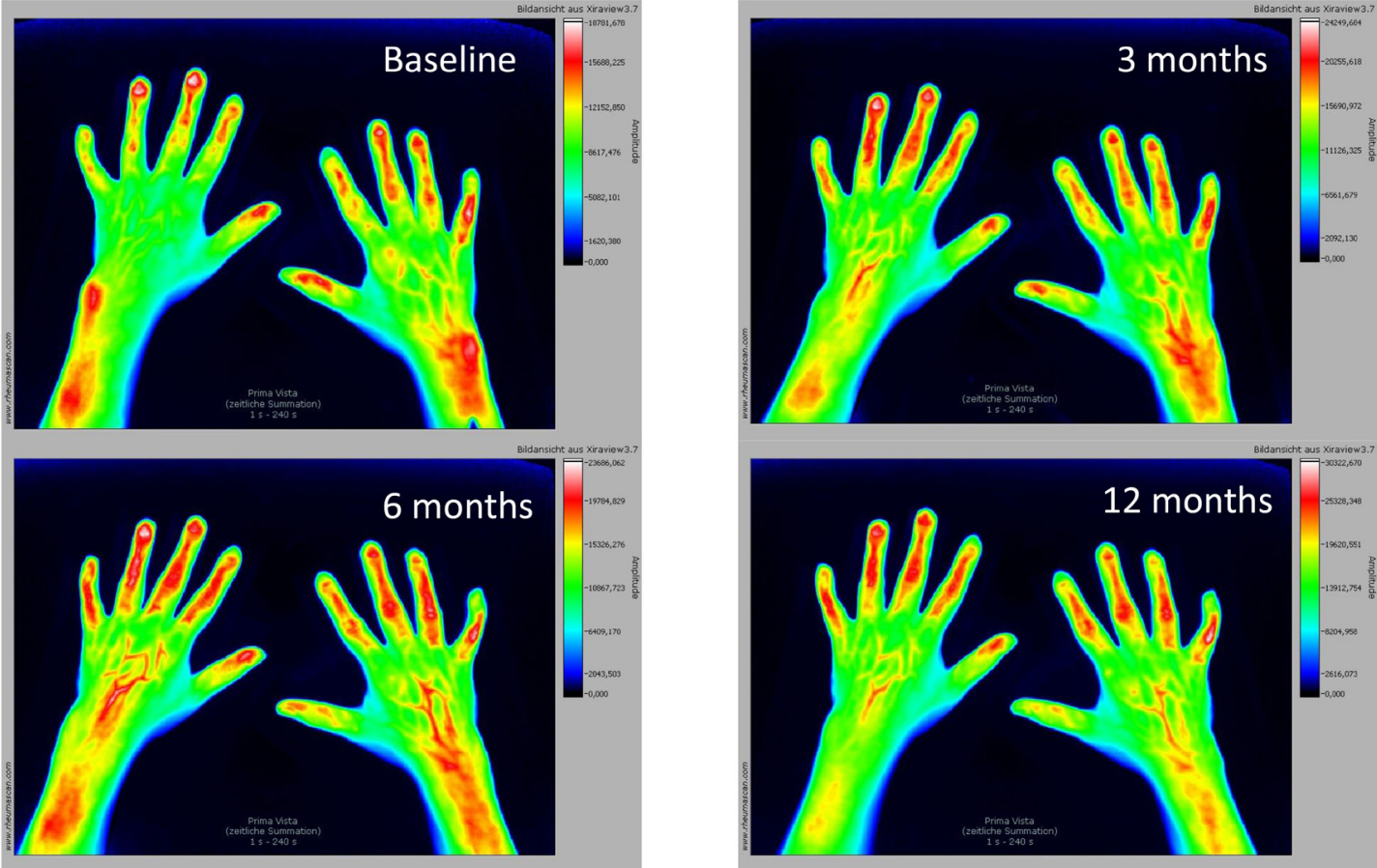

Figure 1 Fluorescence optical imaging in PrimaVista mode over a follow-up of 12 months after rituximab therapy. At baseline, moderate enhancement in both wrists decreasing within 9 months.

a significance for the decreasing US7 score parameters. This could also be observed in the study by Reiche $e t a \tilde{l}$ in which the number of swollen joints and laboratory parameters reduced significantly after 6 months and also the US7 scores decreased without significance. In contrast to the study by Reiche $e t$ al, US7 synovitis score by PD did not show an increase from baseline up to 6 months later. But the US7 synovitis score by GS was-in addition to FOI in PVM - the only parameter in our analyses, which was able to discriminate between groups with and without the need for RTX retherapy. Here, US7 GS synovitis score and FOI in PVM were the only parameters associated with need for retherapy with RTX in patients with RA. This may give FOI an important value for recognising disease activity before patients exhibit clinical signs of flare. Due to the automatic production of PVM, it is a more objective and quickly practicable method for the evaluation of disease activity. Furthermore, with the help of FOI, a scan of all finger and hand joints can be performed within a short time period of $6 \mathrm{~min}$. The procedure is one of the tasks that can be delegated to a trained nurse-in the presence of a doctor in the background. A disadvantage might be the necessary intravenous access making FOI an invasive method, but we have found that this is well accepted by the patient.

If FOI in PVM continues proving an association with RTX retherapy, it would be a good objective method in everyday clinical practice. The adjustment of the phases 1-3 in FOI and their evaluation for every wrist and single finger separately allows a precise estimation of disease

Table 2 Changes between baseline and 6 months follow-up

\begin{tabular}{|c|c|c|c|c|c|c|c|}
\hline & \multicolumn{4}{|c|}{ Univariable } & \multicolumn{3}{|c|}{ Multivariable $^{*}(\mathrm{AUC}=0.80)$} \\
\hline & ORt & AUC & $95 \% \mathrm{Cl}$ & $P$ value & OR† & $95 \% \mathrm{Cl}$ & $P$ value \\
\hline DAS28 & 1.04 & 0.48 & 0.57 to 1.93 & 0.889 & & & \\
\hline $\begin{array}{l}\text { Patient global VAS }(0-100 \\
\mathrm{mm})\end{array}$ & 1.02 & 0.63 & 0.99 to 1.04 & 0.301 & & & \\
\hline ESR (mm/hour) & 1.00 & 0.51 & 0.96 to 1.04 & 0.952 & & & \\
\hline CRP & 0.98 & 0.58 & 0.89 to 1.07 & 0.587 & & & \\
\hline US7 GS synovitis & 0.82 & 0.73 & 0.67 to 1.0 & 0.049 & 0.84 & 0.67 to 1.04 & 0.118 \\
\hline FOI in PVM & 0.84 & 0.78 & 0.72 to 0.98 & 0.031 & 0.84 & 0.71 to 0.99 & 0.037 \\
\hline
\end{tabular}

*Multivariable logistic regression model included the significant variables from univariable analyses.

†OR for increase of 1 unit.

CRP, C reactive protein; DAS28, Disease Activity Score 28; ESR, erythrocyte sedimentation rate; FOI, fluorescence optical imaging; GS, greyscale; PVM, PrimaVista mode; RTX, rituximab; US7, ultrasound seven joint score; VAS, visual analogue scale. 
activity; however, these phases do not seem to be meaningful for the prediction of retherapy to RTX according to the present results. Overall, the evaluation of the automatic PVM might save a lot of time since it is the quickest method in the systematic FOI evaluation due to the its automatic production by the Xiraview software. The results in the group without retherapy are in discrepancy to the results of a previous study of our group on treatment monitoring in early RA. ${ }^{16}$

In this, we found a statistically significant reduction of FOI phase 1 from baseline to follow-up in all patients, regardless EULAR response criteria by DAS28, while phase 2 remained stable within 1 year. A possible explanation for this might be the different patient population. While the patients in the current study have a disease duration of approximatively 15 years, in the previous study we investigated early RA under 1 year of disease duration. Werner et al already discussed that phase 1 indicates active inflammation. ${ }^{12}$ The presentation of active inflammation in phase 1 may also explain why it is reduced in the group of retherapy as a possible low response to therapy, although not significantly, while phase 2 as a possible presentation of subclinical activity and sign of non-response increases, though, without significance.

Next to the already-named invasive character of the FOI method, another limitation of the present study is the limited sample size in this first study addressing the evaluation RTX retherapy in FOI. Furthermore, the univariable analyses may be limited in interpretation. However, an extensive multivariable modelling was not possible due to the limited sample size. Therefore, we established a multivariable model including the significant variables (FOI in PVM and US7 GS synovitis) from univariable analyses. In addition, 17 patients had already received RTX before, which might be another limitation. It would be interesting to assess the association of FOI parameters of RA patients with the need for RTX re-therapy in patients without having RTX before.

To summarise, it can be stated that FOI in PVM and also US7 GS synovitis may be able to discriminate between groups with and without need for RTX retherapy better than other included imaging, clinical and laboratory parameters. At the same time, FOI is a more objective tool, while DAS28, patient's VAS, and CRP also depend on other influence (ie, psychological, infectious) factors. Consideration should therefore be given to including objective factors such as FOI in PVM in the decision on RTX retherapy. In order to fully consolidate these results, further FOI studies on larger scales are required.

\footnotetext{
Author affiliations

${ }^{1}$ Department of Rheumatology and Clinical Immunology, Charité -

Universitätsmedizin Berlin, Berlin, Germany

${ }^{2}$ Department of Internal Medicine - Rheumatology and Clinical Immunology, ParkKlinik Weißensee, Berlin, Germany

${ }^{3}$ Deutsches Rheumaforschungszentrum (DRFZ) Berlin, A Leibniz Institute, Berlin, Germany

${ }^{4}$ Institute for Social Medicine, Epidemiology and Health Economics, Charité Universitätsmedizin Berlin, Berlin, Germany
}

Acknowledgements We would like to thank the patients' advisers and all patients who voluntarily participated in the study.

Contributors SLRA, A-MG and S0 contributed substantially to the conception and design of the study. SLRA, A-MG, JK and SO made substantial contributions to the acquisition, analysis and interpretation of data. JK performed the statistical analyses. SLRA, A-MG and SO drafted the paper. SLRA, A-MG, GRB, PH, GS, SH, MB and $\mathrm{SO}$ revised the article for important intellectual content. All authors gave final approval of the version to be published and agreed to be accountable for all aspects of the work in ensuring that questions related to the accuracy or integrity of any part of the work are appropriately investigated and resolved.

Funding The funding sources had no role in the design and conduct of the study; collection, management, analysis and interpretation of the data; preparation, review or approval of the manuscript; or decision to submit the manuscript for publication.

Competing interests None declared.

Patient consent for publication Not required.

Ethics approval Ethical approval for the study was given by the local ethical committee of the Charité - Universitätsmedizin Berlin; Germany (EA 1/193/10).

Provenance and peer review Not commissioned; externally peer reviewed.

Data availability statement Data are available upon reasonable request. Please contact the following authors for data requests: Schahrasad Lisa Ridha Ali (s.l. ridhaali@gmail.com) or Sarah Ohrndorf (sarah.ohrndorf@charite.de)

Supplemental material This content has been supplied by the author(s). It has not been vetted by BMJ Publishing Group Limited (BMJ) and may not have been peer-reviewed. Any opinions or recommendations discussed are solely those of the author(s) and are not endorsed by BMJ. BMJ disclaims all liability and responsibility arising from any reliance placed on the content. Where the content includes any translated material, BMJ does not warrant the accuracy and reliability of the translations (including but not limited to local regulations, clinical guidelines, terminology, drug names and drug dosages), and is not responsible for any error and/or omissions arising from translation and adaptation or otherwise.

Open access This is an open access article distributed in accordance with the Creative Commons Attribution Non Commercial (CC BY-NC 4.0) license, which permits others to distribute, remix, adapt, build upon this work non-commercially, and license their derivative works on different terms, provided the original work is properly cited, appropriate credit is given, any changes made indicated, and the use is non-commercial. See: http://creativecommons.org/licenses/by-nc/4.0/.

ORCID iDs

Gerd R Burmester http://orcid.org/0000-0001-7518-1131

Sarah Ohrndorf http://orcid.org/0000-0001-5943-4688

\section{REFERENCES}

1 Smolen JS, Landewé R, Bijlsma J, et al. EULAR recommendations for the management of rheumatoid arthritis with synthetic and biological disease-modifying antirheumatic drugs: 2016 update. Ann Rheum Dis 2017;76:960-77.

2 Buch MH, Smolen JS, Betteridge N, et al. Updated consensus statement on the use of rituximab in patients with rheumatoid arthritis. Ann Rheum Dis 2011;70:909-20.

3 Cohen SB, Emery P, Greenwald MW, et al. Rituximab for rheumatoid arthritis refractory to anti-tumor necrosis factor therapy: results of a multicenter, randomized, double-blind, placebo-controlled, phase III trial evaluating primary efficacy and safety at twenty-four weeks. Arthritis Rheum 2006;54:2793-806.

4 van Gestel AM, Prevoo ML, van 't Hof MA, et al. Development and validation of the European League against rheumatism response criteria for rheumatoid arthritis. Comparison with the preliminary American College of rheumatology and the world health Organization/International League against rheumatism criteria. Arthritis Rheum 1996;39:34-40.

5 Reiche BE, Ohrndorf S, Feist E, et al. Usefulness of power Doppler ultrasound for prediction of re-therapy with rituximab in rheumatoid arthritis: a prospective study of longstanding rheumatoid arthritis patients. Arthritis Care Res 2014;66:204-16.

6 Backhaus M, Ohrndorf S, Kellner $\mathrm{H}$, et al. Evaluation of a novel 7-joint ultrasound score in daily rheumatologic practice: a pilot project. Arthritis Rheum 2009;61:1194-201.

7 Backhaus TM, Ohrndorf S, Kellner H, et al. The US7 score is sensitive to change in a large cohort of patients with rheumatoid arthritis over 12 months of therapy. Ann Rheum Dis 2013;72:1163-9. 
8 Ohrndorf S, Fischer IU, Kellner $\mathrm{H}$, et al. Reliability of the novel 7-joint ultrasound score: results from an inter- and intraobserver study performed by rheumatologists. Arthritis Care Res 2012;64:1238-43.

9 Ziswiler H-R, Aeberli D, Villiger PM, et al. High-resolution ultrasound confirms reduced synovial hyperplasia following rituximab treatment in rheumatoid arthritis. Rheumatology 2009;48:939-43.

10 Bøyesen P, Haavardsholm EA, van der Heijde D, et al. Prediction of MRI erosive progression: a comparison of modern imaging modalities in early rheumatoid arthritis patients. Ann Rheum Dis 2011;70:176-9.

11 Werner SG, Langer H-E, Ohrndorf S, et al. Inflammation assessment in patients with arthritis using a novel in vivo fluorescence optical imaging technology. Ann Rheum Dis 2012;71:504-10.

12 Werner S, Langer HE, Schott P. Indocyanine green-enhanced fluorescence optical imaging in patients with early and very early arthritis. Arthritis Rheum 2013;66:3036-44.
13 Aletaha D, Neogi T, Silman AJ, et al. 2010 rheumatoid arthritis classification criteria: an American College of Rheumatology/ European League against rheumatism collaborative initiative. Ann Rheum Dis 2010;69:1580-8.

14 Arnett FC, Edworthy SM, Bloch DA, et al. The American rheumatism association 1987 revised criteria for the classification of rheumatoid arthritis. Arthritis \& Rheumatism 1988;31:315-24.

15 Chatzidionysiou K, Lie E, Nasonov E, et al. Highest clinical effectiveness of rituximab in autoantibody-positive patients with rheumatoid arthritis and in those for whom no more than one previous TNF antagonist has failed: pooled data from 10 European registries. Ann Rheum Dis 2011;70:1575-80.

16 Glimm A-M, Sprenger LI, Haugen IK, et al. Fluorescence optical imaging for treatment monitoring in patients with early and active rheumatoid arthritis in a 1-year follow-up period. Arthritis Res Ther 2019;21:209. 